\title{
Microscopy Assists Understanding Important Aspects of Bioenergy Grasses
}

Gautam Sarath ${ }^{1 *}$, Lisa M. Baird ${ }^{2}$, Han Chen ${ }^{3}$, Nathan A. Palmer ${ }^{1}$, Serge J. Edmé1 and Robert B. Mitchell ${ }^{1}$

${ }^{1}$ Wheat, Sorghum, and Forage Research Unit, USDA-ARS, Lincoln, NE, USA.

2. Biology Department, University of San Diego, San Diego, CA, USA.

3. Penn State College of Medicine, Hershey, PA, USA.

* Corresponding author: Gautam.Sarath@ars.usda.gov

Switchgrass (Panicum virgatum L.) is a polyploid, perennial grass with multiple end uses, with good potential to be grown as a source of biomass for biofuels. Over the course of the last decade or so, significant new genetic, genomic and functional genomic resources have emerged for switchgrass [1]. Despite these successes at the molecular level, there are many aspects of switchgrass biology and biomass deconstruction that have and can benefit from detailed microscopic analyses. This presentation will highlight data obtained at the ARS-Lincoln location using microscopic techniques to investigate switchgrass and sorghum [Sorghum bicolor (L.) Moench].

A basic unit of the aerial portion of the grass tiller (stem) is a phytomer (node + internode and leaf). Each tiller normally consists of several phytomers. On a reproductive tiller the emergence of phytomers ceases when the apical meristem forms flowering structures; however individual internodes on the flowering tiller continue to add secondary cell walls (cellulose, hemicellulose and lignin) up until full leaf senescence, thereby increasing plant biomass. Switchgrass and sorghum genotypes can differ significantly in the amount of lignin which impacts their biofuel potential and consequently breeding for low lignin genotypes has been a significant focus. Both TEM and SEM have been used to study the responses of high and low lignin containing biomass to dilute acid pretreatment [2-3]. These data provided the first evidence for how sorghum and switchgrass biomass deconstruct during dilute acid pretreatment and demonstrated that cell wall architecture and stem anatomy play a significant role in determining biomass quality [3]. Light microscopy of histochemically stained stem cross-sections and confocal laser-scanning microscopy (CLSM) of unstained stem cross-sections have been a staple in identifying changes in secondary cell walls. Using CLSM, it has been possible to differentiate switchgrass genotypes based on stem characteristics (Figure 1) and evaluate the progeny arising from crossing two plants with divergent stem anatomies. Anticipated future experiments will combine CLSM and an enzyme-antibody approach to evaluate how effectively cellulases (enzymes that breakdown cellulose into simpler sugars) can penetrate different cell type in switchgrass stems. The overarching goal is to bridge knowledge gaps on how the plant genetics controlling stem anatomy and cell wall architecture impact biomass quality and deconstruction.

Other applications of microscopy include the study of switchgrass seed germination [4], interactions with aphids [5] and SEM of rhizomes [1]. Immunohistochemistry to document changes in key proteins during switchgrass seed germination (Figure 2), are being extended to other aspects of switchgrass stress responses.

In collaboration with Dr. Ryan Tappero (Lead scientist, XFM beamline, Brookhaven National Laboratory) some investigation of mineral movement in switchgrass cultivars was undertaken (Figure 3). The goal of this project is to study the dynamics of mineral transport during switchgrass tiller senescence. 
References:

[1] G Sarath, LM Baird and RB Mitchell RB, Plant Science 217-218 (2014), p. 140.

[2] BS Dien et al., BioEnergy Research 2 (2009), p.153.

[3] G Sarath et al., Bioresource Technology 102 (2011), p. 9579.

[4] G Sarath et al., Planta 226 (2007), p. 697.

[5] KG Koch et al., BioEnergy Research 11 (2017), p. 480.
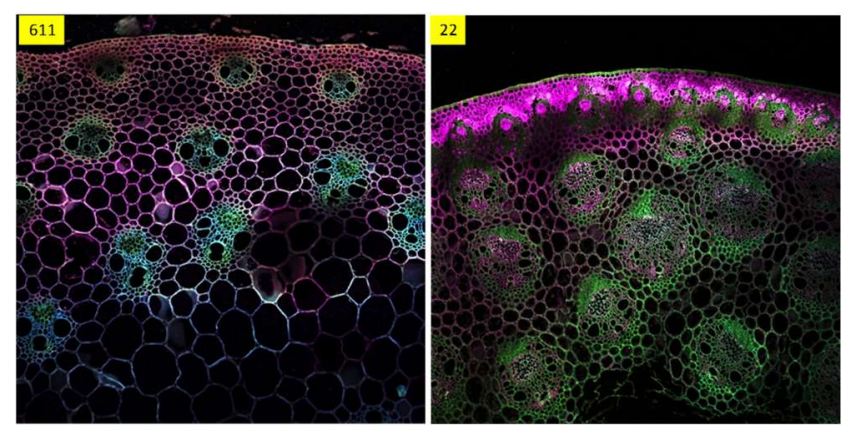

Figure 1. CSLM of cross sections of switchgrass internodes from two parent plants with differing anatomies and distribution of cell types.
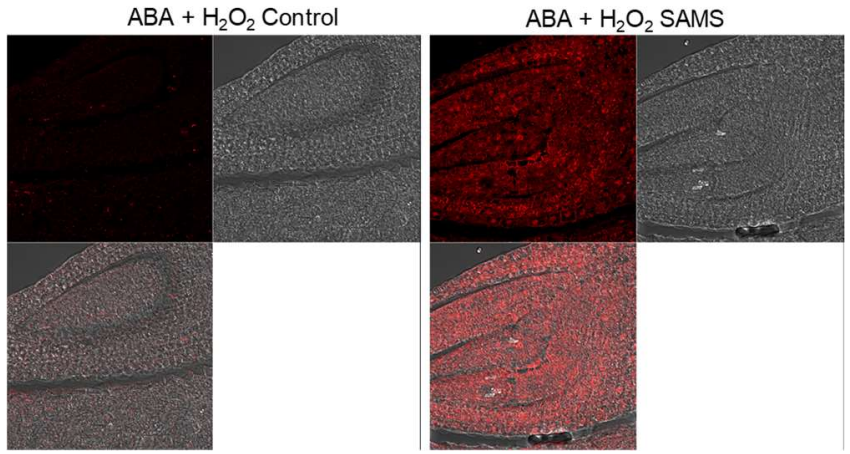

Figure 2. Immunolocalization of s-adenosylmethionine synthase (SAMS) in germinating switchgrass seeds when treated with abscisic acid (ABA) and hydrogen peroxide $\left(\mathrm{H}_{2} \mathrm{O}_{2}\right)$.

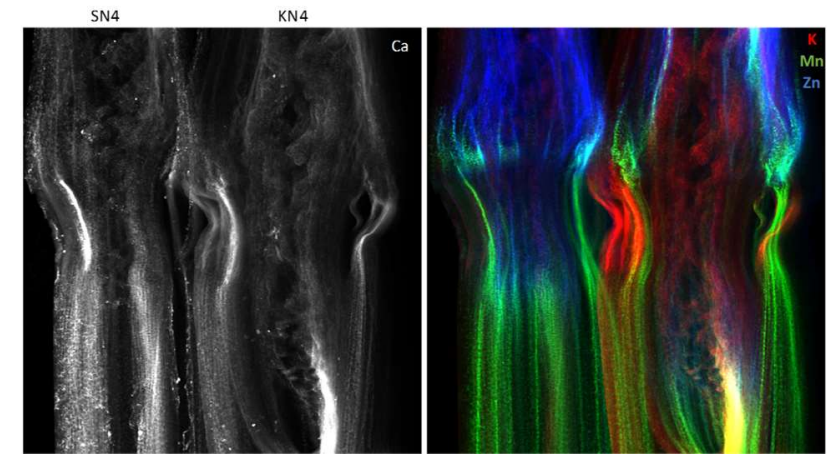

Figure 3. X-ray fluorescence of minerals in nodes and internodes of switchgrass cultivars. Right panel is Calcium. Left panel is potassium (red), manganese (green) and zinc (blue). Images courtesy Dr. Ryan Tappero, BNL. 